\title{
FORMULATION OF RIZATRIPTAN BENZOATE SUBLINGUAL TABLETS PREPARED BY DIRECT COMPRESSION WITH DIFFERENT BIOADHESIVE POLYMER: IN VITRO AND EX VIVO EVALUATION
}

\section{HARMANPREET SINGH ${ }^{1}$, POOJA JAISWAL ${ }^{2}$, SUKSHAM GUPTA ${ }^{2 *}$, SIMERJIT SINGH ${ }^{3}$}

\begin{abstract}
${ }^{1}$ Department of Pharmaceutics, Lovely Institute of Technology (Pharmacy), Lovely Professional University, Phagwara, Punjab, India. ${ }^{2}$ Department of Pharmaceutics, School of Pharmaceutical Sciences, Lovely Professional University, Phagwara, Punjab, India. ${ }^{3}$ Department of Orthopaedics, Universiti Tunku Abdul Rahman, Kuala Lumpur, Malaysia. Email: sukshamgupta.92@gmail.com
\end{abstract} Received: 14 July 2017, Revised and Accepted: 25 July 2017

\section{ABSTRACT}

Objective: The current investigation deals with formulation and evaluation of fast disintegrating sublingual tablets of rizatriptan benzoate (RTB) to produce its intended therapeutic effect for acute treatment of migraine. When the drug is given by sublingual route, it overcomes the first pass metabolism and quick entry of drug in systemic circulation is obtained. It would result in fast pharmacological response hence faster relief from migraine which is an important criterion in migraine therapy.

Methods: In this study, RTB sublingual tablets were prepared using direct compression process using various bioadhesive polymers such as sodium carboxymethyl cellulose, hydroxyl propyl methyl cellulose-K4M, and chitosan at various concentration ranging $0.5-5 \% \mathrm{w} / \mathrm{w}$ along with sodium starch glycolate (SSG) or cross carmellose sodium (CCS) as super disintegrants at different concentration ranging 2-8\% w/w.

Results: The tablets disintegrated quickly and dissolution tests conclude that RTB was released from the formulation within the compendial limits. The formulations batches $\left(\mathrm{A}_{8}\right.$ and $\left.\mathrm{B}_{8}\right)$ containing $2 \% \mathrm{w} / \mathrm{w}$ chitosan along with $2 \% \mathrm{w} / \mathrm{w} \mathrm{SSG}$ or CCS which disintegrate rapidly and show high dissolution and ex vivo permeation were selected as optimized formulations.

Conclusion: The results obtained from the study showed that the bioavailability problem of the drug has been solved as the drug is given by sublingual route and it directly enters into systemic circulation. Furthermore, the formulation overcomes the problems associated with migraine attack as fast disintegrating technology is used.

Keywords: Rizatriptan benzoate, Migraine, Bioadhesive polymers, Sublingual tablet.

(C) 2017 The Authors. Published by Innovare Academic Sciences Pvt Ltd. This is an open access article under the CC BY license (http://creativecommons. org/licenses/by/4. 0/) DOI: http://dx.doi.org/10.22159/ajpcr.2017.v10s4.21334

\section{INTRODUCTION}

Migraine is a brain disorder which is by recurrentattacks of headache and various problems related to autonomic nervous distinguished system such as sensitivity to light (photophobia), nausea, visual disturbances, and other neurological symptoms. The quality of life of migraineur is significantly affected by an untreated migraine attack with $4-72 \mathrm{hrs}$ of duration. According to several surveys, patients routinely experience the ill effects of the migraine attack as bring the most extreme they have ever experienced. In such cases, a quick onset of pharmacological responses required from drugs $[1,2]$. This can successfully be accomplished by parenteral administration, yet this technique may not generally be helpful for the patient. Therefore, a non-parenteral and convenient dosage form have been developed, i.e., sublingual dosage form in which drug is administered beneath the tongue from where it immediately reaches the systemic circulation thus providing quick onset of action [2-4]. The reason behind this quick onset of action is due to thin sublingual mucosa $(190 \mu \mathrm{m})$ as compared to buccal mucosa $(500-800 \mu \mathrm{m})$ and abundance of blood supply in sublingual region which results in high plasma drug concentration due to maximum drug absorption [5]. One issue related with sublingual medication conveyance is the way that the patient tends to automatically swallow fluids more prominent than $200 \mu \mathrm{L}$ and quick disposal of drugs because of the flushing activity of salivation because of which the drug to be distributed using the sublingual course is expelled from the oral cavity and enters the gastrointestinal tract. To ensure a more intense contact of the formulation with the sublingual mucosa, the formulation should adhere to the moist surface of mucosa and should resist the flushing action of saliva. To overcome this disadvantage, certain bioadhesive polymers such as chitosan, sodium carboxymethyl cellulose (NaCMC), and hydroxyl propyl methyl cellulose-K4M (HPMC$\mathrm{K} 4 \mathrm{M}$ ) were used in formulations [6-10].

The rizatriptan benzoate (RTB) is a potent and selective $5-\mathrm{HT}_{1 \mathrm{~B} / 1 \mathrm{D}}$ receptor agonist. It is used for treating acute migraine with and without aura and minimising migraine symptoms, including pain, nausea, and photophobia or phonophobia. The half life of rizatriptan is 2-3 hrs and absorption is rapid up to $90 \%$, but absolute bioavailability is low, i.e., $47 \%$ because of high first pass effect when taken orally [11,12].

The objective of our study is to develop RTB sublingual tablets which bypass the first pass metabolism and accomplished the quick onset of activity. The RTB sublingual tablets were prepared using bioadhesive polymers such as chitosan, NaCMC, and HPMC-K4M along with superdisintegrants sodium starch glycolate (SSG) and cross carmellose sodium (CCS). Bioadhesive polymers are used in low concentration so that characteristics of sublingual tablets such as disintegration and dissolution is not affected significantly and simultaneously it provides long contact to sublingual mucosa [13]. These developed tablets were then evaluated on the basis of physiochemical parameters, in vitro dissolution and ex vivo permeation study.

\section{MATERIALS AND METHODS}

Materials

Rizatriptan is obtained as a gift sample from SMS Pharmaceuticals, Hyderabad. The bioadhesive polymers Chitosan was purchased from Shanghai Biochemicals Pvt. Ltd., India. HPMC-K4M was purchased from 
CDH Pvt. Ltd, New Delhi, India. NaCMC and Spray-dried mannitol were purchased from Signet Chemical Corporation Pvt. Ltd, Mumbai. The superdisintegrants SSG and CCS were being purchased from and Loba Chemie Pvt. Ltd, Mumbai, India. Microcrystalline cellulose (MCC) was purchased from Arihant Trading Co., Mumbai, India, and magnesium stearate was purchased from S.D. Fine Chem. Ltd, Mumbai, India.

\section{Formulation of rizatriptan sublingual tablets}

Sublingual tablets of RTB were processed by direct compression method. Accurate amount of all the ingredients except magnesium stearate were passed over mesh \#60 and mixed homogeneously using geometric dilution. At last, magnesium stearate was added to lubricate and mixed well. The blended material was directly compressed by a four station tablet punching machine fitted with $6 \mathrm{~mm}$ flat faced punch and die set. The compression force and mass of all tablets were kept stable with each tablet containing RTB equivalent to $5 \mathrm{mg}$ of rizatriptan. The compositions of different formulations are given in Tables 1-3. The concentration of superdisintegrants was optimized on the basis of disintegration time from the formulation batches as shown in Table 1. After optimizing the concentration of superdisintegrants, the type and concentration of bioadhesive polymers was then optimized as given in Tables 2 and 3. Batches containing SSG as superdisintegrant were coded as " $\mathrm{A}$ " while batches containing CCS as superdisintegrant were coded as "B."

Determination of physicochemical parameters of tablets containing bioadhesive polymer

The drug content uniformity of the formulation was determined by dissolving the powdered tablet in $0.1 \mathrm{~N} \mathrm{NaOH}$ solution and sonicated for 20 minutes in ultra sonicator bath. The solution was then filtered using $0.45 \mu \mathrm{m}$ nylon filter, and the filtrate was subjected to necessary dilutions and the analysis was done by ultraviolet (UV)-spectrophotometer at $226 \mathrm{~nm}$.

By using digital vernier caliper, the thickness of the tablets of all the prepared batches was carried by placing it perpendicular to the diameter. Measurement was done of ten tablets for each batch $(\mathrm{n}=10)$. Allowable variation mentioned in literature is $\pm 5 \%$ [14]

Weight variation test was performed by weighing 20 tablets which were selected randomly from each batch, and the individual tablet weights were then compared with the calculated average weights. The percentage weight variation of each batch was then calculated.

Hardness is performed to evaluate mechanical shock and friability test is to check the impact of friction and shocks, which may frequently cause tablet to chip, cap or break. Hardness of tablet of each batch was measured with the help of Monsanto hardness tester. It was expressed in $\mathrm{kg} \mathrm{cm}^{-2}$ and study was performed in replicate of 10 . Friability test was done by placing preweighed sample of tablets with approximately weight of $6.5 \mathrm{~g}$ in the Roche type friabilator, which was subjected to 100 revolutions. After rotations, the tablets were dedusted and the percent friability was then calculated by reweighing the tablets.

\section{Wetting time}

The wetting time of the tablets was assessed $(n=6)$. This trial impersonates the activity of saliva in contact with the formulation. A Whatman channel paper plate collapsed once oppositely was set in a Petri dish of $7.7 \mathrm{~cm}$ in breadth. $8 \mathrm{ml}$ of water with the water solvent color, i.e., rhodamine B was placed on the channel paper in the Petri dish. The tablet was then deliberately kept on the channel paper and time for full wetting was measured. The presence of color on the surface of tablet was taken as a sign of full wetting [15].

\section{In vitro disintegration time}

In vitro disintegration time was calculated for tablets of each batch using disintegration apparatus in 6.8 phosphate buffer being maintained at $37 \pm 0.5^{\circ} \mathrm{C}[16]$

\section{In vitro dissolution studies}

Dissolution study of tablets of various batches was performed in $900 \mathrm{ml}$ of $\mathrm{pH} 6.8$ phosphate buffer as a media maintained at $37 \pm 0.5^{\circ} \mathrm{C}$ using

Table 1: Formulation composition of rizatriptan sublingual tablets for optimizing the concentration of superdisintegrants

\begin{tabular}{|c|c|c|c|c|c|c|c|c|}
\hline \multirow[t]{2}{*}{ Component } & \multicolumn{8}{|c|}{ Quantity (mg/tab) } \\
\hline & $\mathrm{C}_{1}$ & $\mathrm{C}_{2}$ & $\mathrm{C}_{3}$ & $\mathrm{C}_{4}$ & $\mathrm{C}_{5}$ & $\mathrm{C}_{6}$ & $\mathrm{C}_{7}$ & $\mathrm{C}_{8}$ \\
\hline RTB & 7.25 & 7.25 & 7.25 & 7.25 & 7.25 & 7.25 & 7.25 & 7.25 \\
\hline SSG & 2 & 4 & 6 & 8 & - & - & - & - \\
\hline CCS & - & - & - & - & 2 & 4 & 6 & 8 \\
\hline SDM & 61.43 & 60.03 & 58.63 & 57.23 & 61.43 & 60.03 & 58.63 & 57.23 \\
\hline MCC & 26.32 & 25.73 & 24.98 & 24.38 & 26.32 & 25.73 & 24.98 & 24.38 \\
\hline CSD & 2 & 2 & 2 & 2 & 2 & 2 & 2 & 2 \\
\hline MS & 1 & 1 & 1 & 1 & 1 & 1 & 1 & 1 \\
\hline Total weight & 100 & 100 & 100 & 100 & 100 & 100 & 100 & 100 \\
\hline
\end{tabular}

RTB: Rizatriptan benzoate, SSG: Sodium starch glycolate, CCS: Cross carmellose sodium, SDM: Spray dried mannitol, MCC: Microcrystalline cellulose burst, CSD: Colloidal silicon dioxide, MS: Magnesium stearate

Table 2: Formulation composition of rizatriptan sublingual tablets containing $2 \% \mathrm{w} / \mathrm{w}$ SSG as superdisintegrants and variable concentration of different bioadhesive polymers

\begin{tabular}{|c|c|c|c|c|c|c|c|c|c|}
\hline \multirow[t]{2}{*}{ Component } & \multicolumn{9}{|c|}{ Quantity (mg/tab) } \\
\hline & $A_{1}$ & $\mathbf{A}_{2}$ & $\mathbf{A}_{3}$ & $\mathrm{~A}_{4}$ & $\mathbf{A}_{5}$ & $\mathbf{A}_{6}$ & $\mathbf{A}_{7}$ & $\mathbf{A}_{8}$ & $A_{9}$ \\
\hline RTB & 7.25 & 7.25 & 7.25 & 7.25 & 7.25 & 7.25 & 7.25 & 7.25 & 7.25 \\
\hline HPMC-K4M & - & - & - & 0.5 & 2 & 5 & - & - & - \\
\hline Chitosan & - & - & - & - & - & - & 0.5 & 2 & 5 \\
\hline SSG & 2 & 2 & 2 & 2 & 2 & 2 & 2 & 2 & 2 \\
\hline SDM & 61.08 & 60.03 & 57.40 & 61.08 & 60.03 & 57.40 & 61.08 & 60.03 & 57.40 \\
\hline MCC & 26.18 & 25.73 & 24.83 & 26.18 & 25.73 & 24.83 & 26.18 & 25.73 & 24.83 \\
\hline CSD & 2 & 2 & 2 & 2 & 2 & 2 & 2 & 2 & 2 \\
\hline MS & 1 & 1 & 1 & 1 & 1 & 1 & 1 & 1 & 1 \\
\hline Total weight & 100 & 100 & 100 & 100 & 100 & 100 & 100 & 100 & 100 \\
\hline
\end{tabular}

RTB: Rizatriptan benzoate, NaCMC: Sodium carboxymethyl cellulose, HPMC-K4M: Hydroxy propyl methyl cellulose-K4M, SSG: Sodium starch glycolate, CCS: Cross carmellose sodium, SDM: Spray dried mannitol, MCC: Microcrystalline cellulose burst, CSD: Colloidal silicon dioxide, MS: Magnesium stearate 
Table 3: Formulation composition of rizatriptan sublingual tablets containing $2 \% \mathrm{w} / \mathrm{w}$ CCS as superdisintegrants and variable concentration of bioadhesive polymers

\begin{tabular}{|c|c|c|c|c|c|c|c|c|c|}
\hline \multirow[t]{2}{*}{ Component } & \multicolumn{9}{|c|}{ Quantity (mg/tab) } \\
\hline & $\mathrm{B}_{1}$ & $\mathbf{B}_{2}$ & $\mathbf{B}_{3}$ & $\mathrm{~B}_{4}$ & $\mathbf{B}_{5}$ & $\mathrm{~B}_{6}$ & $\mathbf{B}_{7}$ & $\mathbf{B}_{8}$ & $\mathbf{B}_{9}$ \\
\hline RTB & 7.25 & 7.25 & 7.25 & 7.25 & 7.25 & 7.25 & 7.25 & 7.25 & 7.25 \\
\hline $\mathrm{NaCMC}$ & 0.5 & 2 & 5 & - & - & - & - & - & - \\
\hline HPMC-K4M & - & - & - & 0.5 & 2 & 5 & - & - & - \\
\hline Chitosan & - & - & - & - & - & - & 0.5 & 2 & 5 \\
\hline CCS & 2 & 2 & 2 & 2 & 2 & 2 & 2 & 2 & 2 \\
\hline SDM & 61.08 & 60.03 & 57.40 & 61.08 & 60.03 & 57.40 & 61.08 & 60.03 & 57.40 \\
\hline MCC & 26.18 & 25.73 & 24.83 & 26.18 & 25.73 & 24.83 & 26.18 & 25.73 & 24.83 \\
\hline CSD & 2 & 2 & 2 & 2 & 2 & 2 & 2 & 2 & 2 \\
\hline MS & 1 & 1 & 1 & 1 & 1 & 1 & 1 & 1 & 1 \\
\hline Total weight & 100 & 100 & 100 & 100 & 100 & 100 & 100 & 100 & 100 \\
\hline
\end{tabular}

RTB: Rizatriptan benzoate, NaCMC: Sodium carboxymethyl cellulose, HPMC-K4M: Hydroxy propyl methyl cellulose-K4M, SSG: Sodium starch glycolate, CCS: Cross carmellose sodium, SDM: Spray dried mannitol, MCC: Microcrystalline cellulose burst, CSD: Colloidal silicon dioxide, MS: Magnesium stearate

USP Type II (paddle type) dissolution assembly kept at $50 \mathrm{rpm} .5 \mathrm{ml}$ of the sample was taken at different time interval, i.e., 2, 5, 10, 15 and 20 minutes and replaced with the same volume of fresh buffer. The samples were then filtered through $0.22 \mu \mathrm{m}$ nylon filter, and drug content was analyzed using UV visible spectrophotometer at wavelength of $226 \mathrm{~nm}$. Six replicates were taken to ensure high confidence on result for the dissolution studies [17].

\section{Ex vivo permeation studies}

Ex vivo permeation of all the formulation batches was conducted through porcine oral mucosa (ventral surface of tongue) using Franz diffusion cell. Porcine oral mucosa was chosen as a most appropriate model for the permeation study due to its similarity to the human oral mucosa as far as histological attributes, biochemical structure, and penetrability and also the accessibility and lower cost. The mucosa was extracted and trimmed uniformly from the sides, washed in $\mathrm{pH} 6.8$ phosphate buffer and utilized instantly. The mucosa was mounted between the donor and receptor compartments of Franz diffusion cell. The receptor compartment of the diffusion cell was loaded with pH 7.4 phosphate buffer kept up at $37 \pm 0.5^{\circ} \mathrm{C}$ and hydrodynamics were kept up utilizing magnetic stirrer. The donor compartment was loaded with $2 \mathrm{ml}$ of $\mathrm{pH} 6.8$ phosphate buffer. The RTB tablet of given batch was placed in donor compartment. $3 \mathrm{ml}$ sample from receptor compartment were withdraw at suitable time interval $(2,5,10,20,30,45,60,90,105$ and 120 minutes), which was then replaced with $3 \mathrm{ml}$ of fresh $\mathrm{pH} 7.4$ phosphate buffer. The permeation studies were carried out up to 2 hrs (120 minutes) because the freshly excised porcine oral tissue can remain alive for $2 \mathrm{hrs}$ at $37 \pm 0.5^{\circ} \mathrm{C}[18,19]$. Three replicates for each batch were taken for all permeation studies. The permeability coefficient $\left(\mathrm{K}_{\mathrm{p}}\right)$ was calculated using equation (1) where $\mathrm{J}_{\mathrm{ss}}$ is the steady state flux and $\mathrm{C}_{\mathrm{v}}$ is the total volume in donor compartment. $\mathrm{J}_{\mathrm{ss}}$ was obtained from the slope of the linear portion of the plot between the cumulative amount of Rizatriptan permeated per unit area and time.

$\mathrm{Kp}=\mathrm{J}_{\mathrm{ss}} / \mathrm{C}_{\mathrm{v}}$

\section{Differential scanning calorimetry (DSC)}

The molecular state of the drug was assessed by DSC analysis of placebo tablet, physical blend of drug and excipients, Rizatriptan sublingual tablet, and pure drug using a DSC (DSC 6, Perkin Elmer, USA). All the samples were warmed in hermetically fixed aluminum container with a temperature scope of $35^{\circ} \mathrm{C}-394^{\circ} \mathrm{C}$ at a steady rate of $10.0^{\circ} \mathrm{C}$ for every min under nitrogen cleanse at $20 \mathrm{ml} /$ minutes [20].

\section{Accelerated stability studies}

Optimized formulations $\left(A_{8}\right.$ and $\left.B_{8}\right)$ packed in aluminum foil were subjected to accelerated stability study for 3 months as per ICH norms by keeping it in stability chamber kept at a constant temperature of $40^{\circ} \mathrm{C} \pm 2{ }^{\circ} \mathrm{C}$ and relative humidity of $75 \% \pm 5 \%$ RH [21]. For 3 months, samples were taken at regular time interval of 1 month and analyzed for the change in vitro drug release and drug content by procedure stated earlier. Tests were performed in triplicate and mean value of the observed values was noted along with standard deviation.

\section{RESULTS AND DISCUSSION}

Determination of physicochemical parameters

The resulted physical properties of sublingual tablets were compared and are shown in Tables 4-6.

Drug content uniformity test for all the prepared batches was performed as per USP guidelines, and the results were found to be on compliance with USP guidelines. Content uniformity of batches containing SSG varies from $98.02 \%$ to $102.43 \%$ while in case of CCS containing batches it varies from $98.36 \%$ to $104.32 \%$ [14].

Thickness analysis of tablet was performed as per procedure mentioned in literature [12]. Observed variation among different batches was lying in acceptable limits of $\pm 5 \%$.

Weight variation test was performed as per as USP monograph. All the tablets were found to lie within acceptable weight variation limit of $\pm 10 \%$ with respect to average weight [14].

Tablets require certain quality or hardness and a friability so as to withstand mechanical shock of handling in dealing with in assembling, packaging and dispatching. Sufficient hardness and friability are additionally required for buyer acknowledgment [12]. Prepared tablets were found to be in compliance with friability limits $(<1 \%)$ mentioned in literature [14]. Hardness was also analyzed for all the batches using Monsanto hardness tester and were found to be in acceptable limit $\left(3-6 \mathrm{~kg} / \mathrm{cm}^{2}\right)$, which is required to keep up the integrity of tablet.

\section{Wetting time}

There was no significant difference in wetting time between batches with and without bioadhesive polymers. The wetting time values for the prepared tablets of all the formulation batches were found to be in the range of 12-38 seconds. The wetting time was less with $2 \% \mathrm{w} / \mathrm{w}$ NaCMC $\left(\mathrm{A}_{2}\right.$ and $\left.\mathrm{B}_{2}\right), 5 \% \mathrm{w} / \mathrm{w}$ HPMC-K4M $\left(\mathrm{A}_{6}\right.$ and $\left.\mathrm{B}_{6}\right)$, and $5 \% \mathrm{w} / \mathrm{w}$ chitosan $\left(\mathrm{A}_{9}\right.$ and $\mathrm{B}_{9}$ ). It was observed that as the concentration of NaCMC in batches $\left(\mathrm{A}_{3}\right.$ and $\left.\mathrm{B}_{3}\right)$ was made more or $<2 \% \mathrm{w} / \mathrm{w}$ the time taken for wetting was increased. In case of batches containing chitosan and HPMC-K4M as the concentration of bioadhesive polymer decreased below $5 \% \mathrm{w} / \mathrm{w}$ the wetting time was increased. The results of wetting time for various batches are shown in Table 7.

\section{In vitro disintegration time}

The optimized concentration of superdisintegrants was used to optimize the type and concentration of bioadhesive polymers as per Tables 2 and 3. In this study, disintegration time for batches containing SSG $2 \% \mathrm{w} / \mathrm{w}$ as superdisintegrants varies between 12 and 37 seconds and for batches containing CCS $2 \% \mathrm{w} / \mathrm{w}$ as superdisintegrant varies between 14 and 
Table 4: Physicochemical analysis of batches containing superdisintegrant SSG and CCS in different ratio

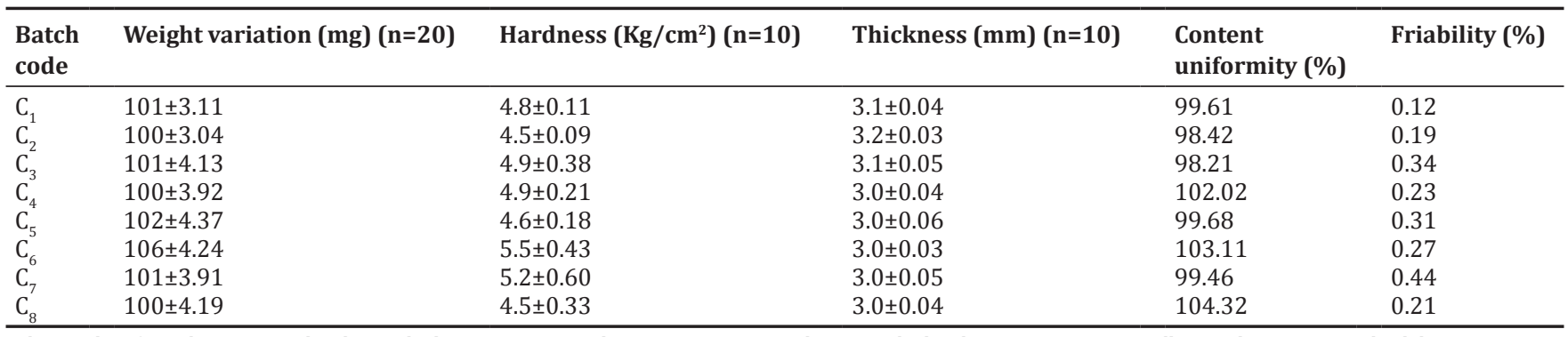

The results of weight variation, hardness, thickness are reported in mean \pm SD, SSG: Sodium starch glycolate, CCS: Cross carmellose sodium, SD: Standard deviation

Table 5: Physicochemical analysis of batches containing SSG (2\% w/w) and bioadhesive polymers

\begin{tabular}{|c|c|c|c|c|c|}
\hline $\begin{array}{l}\text { Batch } \\
\text { code }\end{array}$ & Weight variation $(\mathrm{mg})(\mathrm{n}=20)$ & Hardness $\left(\mathrm{Kg} \mathrm{cm}^{2}\right)(\mathrm{n}=10)$ & Thickness (mm) $(n=10)$ & $\begin{array}{l}\text { Content } \\
\text { uniformity (\%) }\end{array}$ & Friability (\%) \\
\hline $\mathrm{A}_{1}$ & $100 \pm 3.11$ & $5.2 \pm 0.38$ & $3.0 \pm 0.04$ & 98.02 & 0.34 \\
\hline $\mathrm{A}_{2}$ & $100 \pm 3.31$ & $4.1 \pm 0.32$ & $3.2 \pm 0.03$ & 99.71 & 0.27 \\
\hline $\mathrm{A}_{3}^{2}$ & $101 \pm 4.62$ & $4.3 \pm 0.44$ & $3.1 \pm 0.06$ & 101.24 & 0.43 \\
\hline $\mathrm{A}_{4}^{3}$ & $102 \pm 3.76$ & $5.6 \pm 0.40$ & $3.0 \pm 0.04$ & 99.51 & 0.18 \\
\hline$A_{5}^{4}$ & $101 \pm 4.20$ & $4.5 \pm 0.28$ & $3.0 \pm 0.05$ & 102.43 & 0.19 \\
\hline $\mathrm{A}_{6}^{5}$ & $100 \pm 3.01$ & $4.9 \pm 0.61$ & $3.0 \pm 0.03$ & 99.56 & 0.47 \\
\hline $\mathrm{A}_{8}^{7}$ & $100 \pm 4.76$ & $5.1 \pm 0.31$ & $3.1 \pm 0.05$ & 101.42 & 0.22 \\
\hline $\mathrm{A}_{9}^{\circ}$ & $102 \pm 3.69$ & $4.7 \pm 0.56$ & $3.0 \pm 0.04$ & 99.83 & 0.36 \\
\hline
\end{tabular}

The results of weight variation, hardness, thickness are reported in mean \pm SD. SSG: Sodium starch glycolate, SD: Standard deviation

Table 6: Physicochemical analysis of batches containing CCS $(2 \% \mathrm{w} / \mathrm{w})$ and bioadhesive polymers

\begin{tabular}{lllll}
\hline $\begin{array}{l}\text { Batch } \\
\text { code }\end{array}$ & Weight variation (mg) $(\mathbf{n = 2 0 )}$ & Hardness $\left(\mathbf{K g ~ c m}^{2}\right) \mathbf{( n = 1 0 )}$ & Thickness (mm) (n=10) & $\begin{array}{l}\text { Content } \\
\text { uniformity (\%) }\end{array}$ \\
\hline $\mathrm{B}_{1}$ & $102 \pm 4.71$ & $4.2 \pm 0.47$ & $3.0 \pm 0.05$ & 101.39 \\
$\mathrm{~B}_{2}$ & $100 \pm 3.90$ & $4.1 \pm 0.32$ & $3.2 \pm 0.03$ & 98.71 \\
$\mathrm{~B}_{3}$ & $100 \pm 3.45$ & $4.3 \pm 0.63$ & $3.1 \pm 0.06$ & 9.25 \\
$\mathrm{~B}_{4}$ & $101 \pm 3.52$ & $4.6 \pm 0.42$ & $3.0 \pm 0.04$ & 0.28 \\
$\mathrm{~B}_{5}$ & $103 \pm 3.85$ & $4.7 \pm 0.07$ & $3.0 \pm 0.04$ & 0.17 \\
$\mathrm{~B}_{6}$ & $104 \pm 4.47$ & $5.1 \pm 0.26$ & $3.0 \pm 0.03$ & 0.34 \\
$\mathrm{~B}_{7}$ & $100 \pm 3.93$ & $5.2 \pm 0.17$ & $3.0 \pm 0.05$ & 0.18 \\
$\mathrm{~B}_{8}$ & $100 \pm 3.77$ & $5.8 \pm 0.44$ & $3.2 \pm 0.06$ & 0.34 \\
$\mathrm{~B}_{9}$ & $101 \pm 2.38$ & $4.6 \pm 0.36$ & $3.1 \pm 0.04$ & 0.41 \\
\hline
\end{tabular}

The results of weight variation, hardness, thickness are reported in mean \pm SD, SD: Standard deviation, CCS: Cross carmellose sodium

38 seconds as shown in Table 7. According to USP guidelines, sublingual tablets should disintegrate in $<2$ minutes in USP disintegration apparatus equipped with basket rack assembly without plastic disk [13]. Thus, all the batches pass the in vitro disintegration test. The rapid and sudden disintegration of tablets might be due to spray dried mannitol, MCC burst and due to the presence of superdisintegrant (SSG or CCS).

\section{In vitro dissolution test}

The dissolution profile of RTB in all the formulations is shown in Figs. 1 and 2. As mentioned in literature, within 15 minutes the amount of drug dissolved from a sublingual tablet should be more than $80 \%$ [15]. As a result, all batches comply with the above-mentioned criteria, as all the formulation showed above $80 \%$ release within 10 minutes. Quick release of the drug from the formulations can be clarified on the basis of various factors. First, the assembling strategy can be a standout among the most imperative parameters for the quick dissolution. The tablets formulated using direct compression method disintegrates into rizatriptan particles rather than granules that straightforwardly come into contact with dissolution liquid and displays nearly quicker release. From all the polymers containing formulations, the formulation $A_{8}, A_{9}, B_{8}$ and $B_{9}$ containing $2 \% \mathrm{w} / \mathrm{w}$ and $5 \% \mathrm{w} / \mathrm{w}$ chitosan showed the most extreme drug release. The chitosan generally inundates water when it comes in contact with the fluid and burst because of the pressure applied by the capillary action thereby show immediate disintegration of the dosage form.

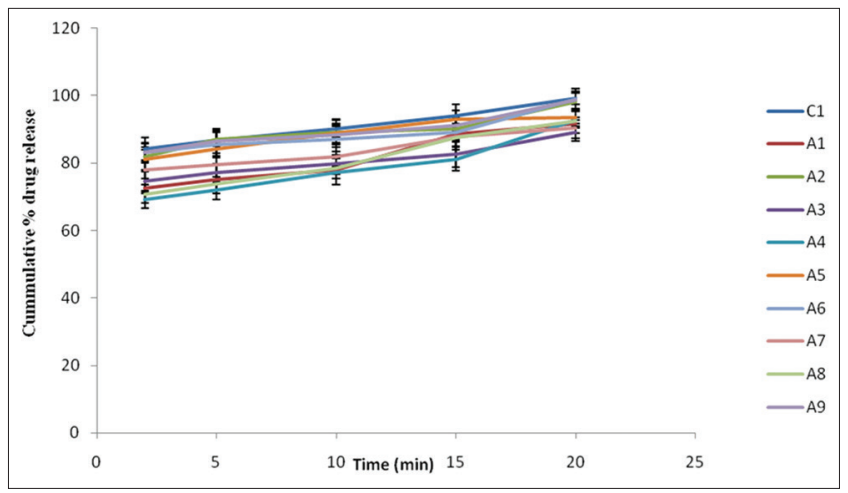

Fig. 1: Dissolution profile of sublingual tablets of rizatriptan benzoate containing sodium starch glycolate $2 \% \mathrm{w} / \mathrm{w}$ with and without bioadhesive polymers

Ex vivo permeation studies

All the batches were further analyzed by performing ex vivo permeability studies through porcine oral mucosa procured from local slaughter house, Jalandhar. The percentage of drug permeated from the formulations after 120 minutes in the vicinity of $23.55 \%$ and $27.95 \%$. Low and 
Table 7: In vitro disintegration time and wetting time of sublingual tablets of RTB

\begin{tabular}{|c|c|c|}
\hline Batch code & $\begin{array}{l}\text { Disintegration } \\
\text { time (seconds) }\end{array}$ & $\begin{array}{l}\text { Wetting } \\
\text { time (seconds) }\end{array}$ \\
\hline $\mathrm{C}_{1}$ & $22 \pm 3.22$ & $17 \pm 0.56$ \\
\hline $\mathrm{C}_{2}$ & $34 \pm 4.76$ & $23 \pm 0.42$ \\
\hline $\mathrm{C}_{3}^{2}$ & $41 \pm 6.34$ & $29 \pm 0.59$ \\
\hline $\mathrm{C}_{4}^{3}$ & $35 \pm 4.67$ & $26 \pm 0.37$ \\
\hline $\mathrm{C}_{5}^{4}$ & $19 \pm 2.83$ & $15 \pm 0.41$ \\
\hline $\mathrm{C}_{6}$ & $39 \pm 7.31$ & $29 \pm 0.54$ \\
\hline $\mathrm{C}_{7}^{6}$ & $38 \pm 5.35$ & $33 \pm 0.23$ \\
\hline $\mathrm{C}_{8}^{\prime}$ & $42 \pm 1.59$ & $28 \pm 0.47$ \\
\hline$A_{1}^{8}$ & $32 \pm 3.98$ & $27 \pm 0.58$ \\
\hline $\mathrm{A}_{2}$ & $23 \pm 9.37$ & $19 \pm 0.60$ \\
\hline $\mathrm{A}_{3}^{2}$ & $34 \pm 1.57$ & $26 \pm 0.33$ \\
\hline $\mathrm{A}_{4}^{3}$ & $48 \pm 2.87$ & $25 \pm 0.54$ \\
\hline$A_{5}^{4}$ & $29 \pm 10.01$ & $37 \pm 0.51$ \\
\hline$A_{6}$ & $25 \pm 1.99$ & $14 \pm 0.56$ \\
\hline$A_{7}^{\circ}$ & $34 \pm 5.72$ & $31 \pm 0.38$ \\
\hline$A_{8}$ & $47 \pm 8.34$ & $24 \pm 0.46$ \\
\hline$A_{9}^{8}$ & $27 \pm 9.47$ & $12 \pm 0.45$ \\
\hline $\mathrm{B}_{1}$ & $35 \pm 4.76$ & $23 \pm 0.50$ \\
\hline $\mathrm{B}_{2}$ & $21 \pm 7.38$ & $19 \pm 0.49$ \\
\hline $\mathrm{B}_{3}^{2}$ & $34 \pm 2.66$ & $33 \pm 0.53$ \\
\hline $\mathrm{B}_{4}^{3}$ & $46 \pm 6.41$ & $38 \pm 0.55$ \\
\hline$B_{5}^{4}$ & $48 \pm 3.77$ & $29 \pm 0.38$ \\
\hline $\mathrm{B}_{6}^{\mathrm{s}}$ & $24 \pm 4.90$ & $17 \pm 0.49$ \\
\hline$B_{7}^{6}$ & $36 \pm 6.45$ & $36 \pm 0.37$ \\
\hline $\mathrm{B}_{8}$ & $43 \pm 2.56$ & $21 \pm 0.58$ \\
\hline $\mathrm{B}_{9}^{8}$ & $26 \pm 7.55$ & $13 \pm 0.52$ \\
\hline
\end{tabular}

For all the batches disintegration and wetting time is reported in mean \pm SD. SD: Standard deviation, RTB: Rizatriptan benzoate

Table 8: Drug release parameters for permeability studies carried out on porcine mucosa $(n=3)$

\begin{tabular}{llll}
\hline Batch & Released (\%) & $\mathbf{J}_{\mathbf{s s}}\left(\boldsymbol{\mu g} / \mathbf{c m}^{2} \mathbf{h r}\right)$ & $\mathbf{K}_{\mathbf{p}}(\mathbf{c m} / \mathbf{h r})$ \\
\hline $\mathrm{C}_{1}$ & $23.68 \pm 4.22$ & $157.3 \pm 11.91$ & $62.92 \pm 5.78$ \\
$\mathrm{C}_{5}$ & $23.55 \pm 3.45$ & $157.8 \pm 17.87$ & $63.12 \pm 3.98$ \\
$\mathrm{~A}_{1}$ & $24.18 \pm 1.98$ & $159.5 \pm 23.12$ & $63.92 \pm 9.77$ \\
$\mathrm{~A}_{2}$ & $25.72 \pm 0.87$ & $247.9 \pm 13.67$ & $99.16 \pm 4.54$ \\
$\mathrm{~A}_{3}$ & $23.67 \pm 0.56$ & $171.4 \pm 15.65$ & $68.56 \pm 6.87$ \\
$\mathrm{~A}_{4}$ & $26.42 \pm 1.65$ & $256.8 \pm 14.76$ & $102.72 \pm 7.45$ \\
$\mathrm{~A}_{5}$ & $25.66 \pm 0.59$ & $279.4 \pm 12.68$ & $111.76 \pm 3.26$ \\
$\mathrm{~A}_{6}$ & $25.41 \pm 0.98$ & $282.2 \pm 16.34$ & $112.88 \pm 11.20$ \\
$\mathrm{~A}_{7}$ & $27.91 \pm 2.54$ & $285.9 \pm 22.87$ & $114.36 \pm 6.56$ \\
$\mathrm{~A}_{8}$ & $25.26 \pm 1.76$ & $414.9 \pm 11.87$ & $165.96 \pm 8.52$ \\
$\mathrm{~A}_{9}$ & $27.95 \pm 3.45$ & $348.7 \pm 16.87$ & $139.48 \pm 4.52$ \\
$\mathrm{~B}_{1}$ & $24.88 \pm 0.67$ & $199.1 \pm 12.87$ & $79.64 \pm 3.65$ \\
$\mathrm{~B}_{2}$ & $25.97 \pm 0.98$ & $253.5 \pm 19.98$ & $101.4 \pm 6.56$ \\
$\mathrm{~B}_{3}$ & $25.03 \pm 0.34$ & $194.7 \pm 14.56$ & $77.88 \pm 7.72$ \\
$\mathrm{~B}_{4}$ & $25.69 \pm 2.56$ & $255.4 \pm 16.78$ & $102.16 \pm 8.66$ \\
$\mathrm{~B}_{5}$ & $25.44 \pm 1.65$ & $268.1 \pm 13.65$ & $107.24 \pm 2.76$ \\
$\mathrm{~B}_{6}$ & $25.99 \pm 0.93$ & $273.1 \pm 18.55$ & $109.24 \pm 1.65$ \\
$\mathrm{~B}_{7}$ & $25.32 \pm 2.54$ & $324.2 \pm 10.66$ & $129.68 \pm 5.81$ \\
$\mathrm{~B}_{8}$ & $25.68 \pm 1.49$ & $410.3 \pm 19.77$ & $164.12 \pm 9.62$ \\
$\mathrm{~B}_{9}$ & $25.07 \pm 3.68$ & $357.6 \pm 14.76$ & $143.04 \pm 7.48$ \\
\hline
\end{tabular}

The results of permeation value are reported in mean \pm SD. SD: Standard deviation

moderate release of drug can be credited to little volume $(2 \mathrm{ml})$ in donor compartment due to which the tablets swell. The resulted swollen particles of the tablets have porosity, and the drug discharge through them happens due to dispersion from the openings made by the porosity of matrix. In in vivo conditions, the force being applied by the tongue to the tablet can inhibit swelling and promotes disintegration of tablet and release of drug from the formulation. Then again, Chitosan and HPMCK4M formulations $\left(A_{4}-A_{9}\right.$ and $\left.B_{4}-B_{9}\right)$ showed higher drug release and increased steady state flux $\left(\mathrm{J}_{\mathrm{ss}}\right)$ and permeability coefficient $\left(\mathrm{K}_{\mathrm{p}}\right)$ values

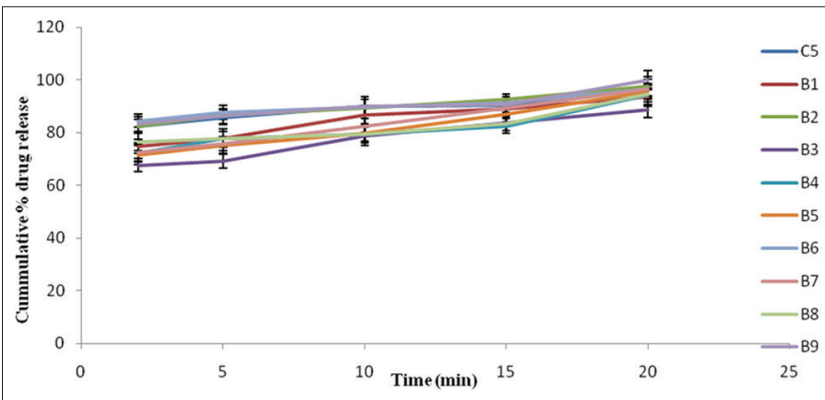

Fig. 2: Dissolution profile of sublingual tablets of rizatriptan benzoate batches containing cross carmellose sodium $2 \% \mathrm{w} / \mathrm{w}$ with and without bioadhesive polymers

contrasted with NaCMC formulations shown in Table 8. Maximum value of $\mathrm{J}_{\mathrm{ss}}$ and $\mathrm{K}_{\mathrm{p}}$ was observed for $\mathrm{A}_{8}$ and $\mathrm{B}_{8}$ batch having $2 \% \mathrm{w} / \mathrm{w}$ chitosan.

DSC

The DSC thermogram of the samples, i.e., pure drug, placebo (tablet), physical mixture of RTB with excipients, and optimized RTB sublingual tablet were studied. The endothermic peak of pure drug was found at $164^{\circ} \mathrm{C}$ whereas in optimized RTB sublingual tablet and physical mixture of RTB with excipients the endothermic peak was observed at $165^{\circ} \mathrm{C}$. The size of peak is small because of the reason that measure of RTB in sublingual tablet and physical blend with drug was about $20 \%$. It demonstrates that drug is present in crystalline form in all the formulations. The presence of peak at $138.8^{\circ} \mathrm{C}$ on all samples except the pure drug was due to the addition of excipients (Fig. 3)

\section{Accelerated stability studies}

There were no physical changes in the appearance and color of tablet. After subjecting the optimized formulation $\left(A_{8}\right.$ and $\left.B_{8}\right)$ to the accelerated stability studies, the results were shown Tables 9 and 10 and Fig. 4. It was found that in percentage drug content and in vitro drug release there were no major changes. Hence, the formulation was found to be stable.

\section{CONCLUSION}

Our research has been made to overcome problem associated with poor drug bioavailability of RTB by giving the drug by sublingual route which will bypass first pass effect; thus drug bioavailability will be enhanced. All batches were made by direct compression method. SSG and CCS were used as superdisintegrants in various concentrations, and an optimum concentration $(2 \% \mathrm{w} / \mathrm{w})$ of superdisintegrants was selected based on disintegration time. Along with these superdisintegrants various bioadhesive polymers such as Chitosan, HPMC-K4M, and NaCMC were used as in different ratio, i.e., $0.5 \% \mathrm{w} / \mathrm{w}, 2 \% \mathrm{w} / \mathrm{w}$, and $5 \% \mathrm{w} / \mathrm{w}$ in tablets so as to enhance the residence time of drug containing particles and overcome the flushing action of saliva. Their concentration was optimized in such a way that they will provide adhesion of generated particles after disintegration of tablet without significantly effecting the disintegration time of tablet. Various parameters were evaluated for each batch such as weight variation, thickness, content uniformity, drug content, in vitro dissolution test, and in vitro disintegration test. The result of these tests has been found in acceptable range as per USP 2007. The formulation containing $2 \% \mathrm{w} / \mathrm{w}$ and $5 \% \mathrm{w} / \mathrm{w}$ chitosan, i.e., $A_{8}, A_{9}, B_{8}$ and $B_{9}$ has shown good dissolution as compared to other batches. The permeability value of formulation containing $2 \% \mathrm{w} / \mathrm{w}$ and $5 \% \mathrm{w} / \mathrm{w}$ of chitosan and HPMC-K4M $\left(\mathrm{A}_{5}, \mathrm{~A}_{6}, \mathrm{~A}_{8}, \mathrm{~A}_{9}, \mathrm{~B}_{5}, \mathrm{~B}_{6}, \mathrm{~B}_{8}\right.$ and $\left.\mathrm{B}_{9}\right)$ was found to be maximum. The formulation with $2 \% \mathrm{w} / \mathrm{W}$ of chitosan $\left(A_{8}\right.$ and $\left.B_{8}\right)$ was selected as optimum formulation as it not only will give effective result such as permeation, dissolution, and disintegration but it is also economical as compared to higher amount of its percentage, i.e., $5 \% \mathrm{w} / \mathrm{w}$ used for batches $A_{9}$ and $B_{9}$. Accelerated stability studies of optimized formulations $\left(A_{8}\right.$ and $\left.B_{8}\right)$ reveals that designed formulations are stable on storage and are capable to give reproducible results. 

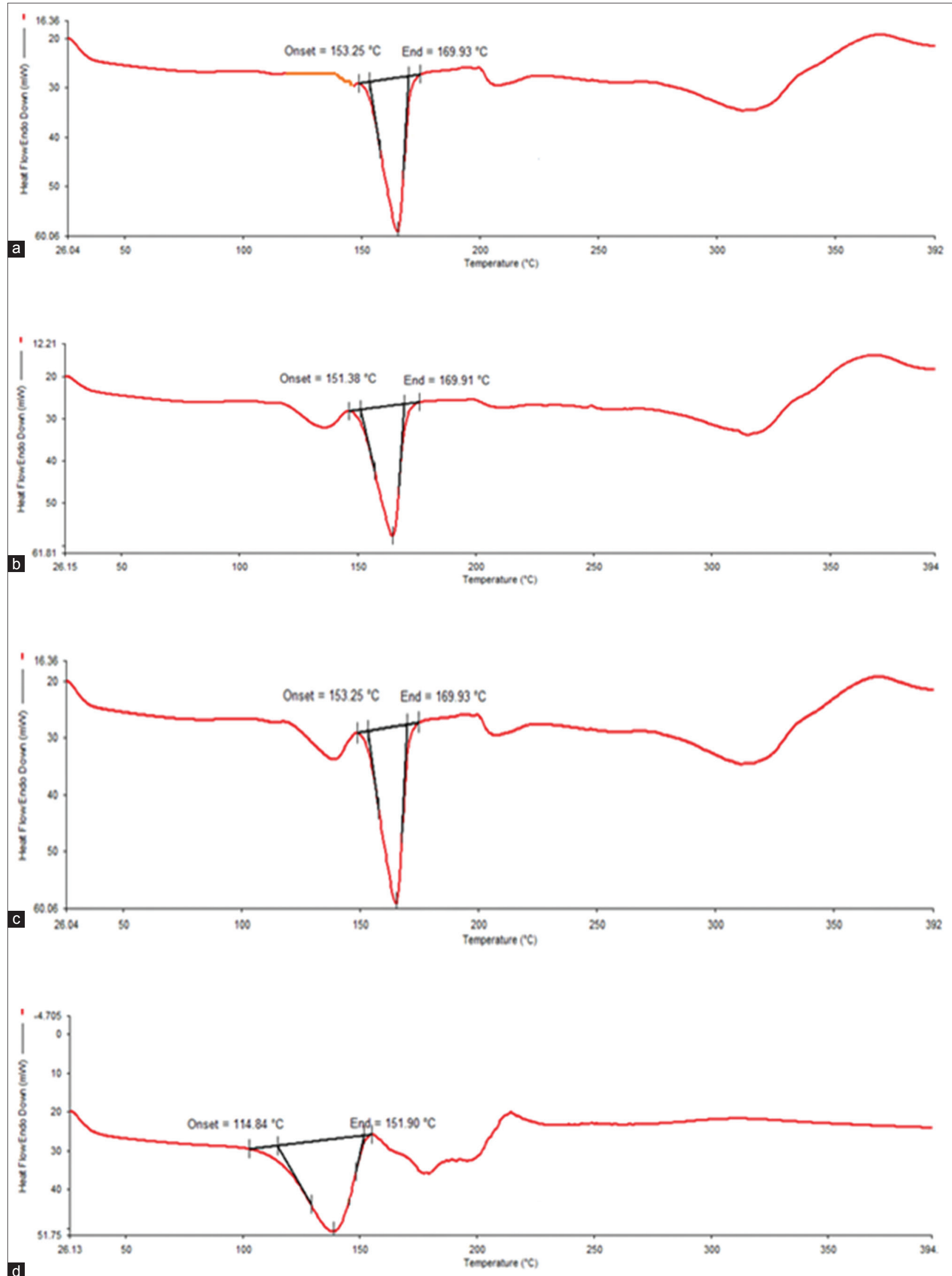

Fig. 3: Differential scanning calorimetry thermogram of (a) pure drug, (b) physical mixture of drug and excipients, (c) rizatriptan benzoate sublingual tablet and (d) placebo tablet 
Table 9: Accelerated stability studies for batch $A_{8}$

\begin{tabular}{lllll}
\hline Parameter & \multicolumn{4}{l}{ Temperature maintained at $\mathbf{4 0} \pm \mathbf{2}^{\circ} \mathbf{C}$; RH maintained at $\mathbf{7 5} \mathbf{5} \mathbf{5 \%} \mathbf{R H}$} \\
\cline { 2 - 5 } & Initial & After $\mathbf{1}$ month & After $\mathbf{2}$ months & After $\mathbf{3}$ months \\
\hline Drug content (\%) & $99.89 \pm 3.24$ & $99.82 \pm 3.19$ & $99.76 \pm 3.16$ & $99.69 \pm 2.27$ \\
\% drug release after 20 minutes & $99.31 \pm 2.15$ & $99.23 \pm 3.21$ & $99.18 \pm 2.18$ & $99.16 \pm 2.25$ \\
\hline
\end{tabular}

RH: Relative humidity

Table 10: Accelerated stability studies for batch $B_{8}$

\begin{tabular}{lllll}
\hline Parameter & \multicolumn{4}{l}{ Temperature maintained at $\mathbf{4 0} \pm \mathbf{2}^{\circ} \mathbf{C}$; RH maintained at $\mathbf{7 5} \mathbf{5} \mathbf{5} \mathbf{~ R H}$} \\
\cline { 2 - 5 } & Initial & After $\mathbf{1}$ month & After $\mathbf{2}$ months & After $\mathbf{3}$ months \\
\hline Drug content (\%) & $99.89 \pm 2.24$ & $99.82 \pm 3.19$ & $99.76 \pm 3.16$ & $99.69 \pm 2.27$ \\
\% Drug release after 20 minutes & $99.91 \pm 3.27$ & $99.86 \pm 2.21$ & $99.71 \pm 3.18$ & $99.68 \pm 3.25$ \\
\hline
\end{tabular}

RH: Relative humidity

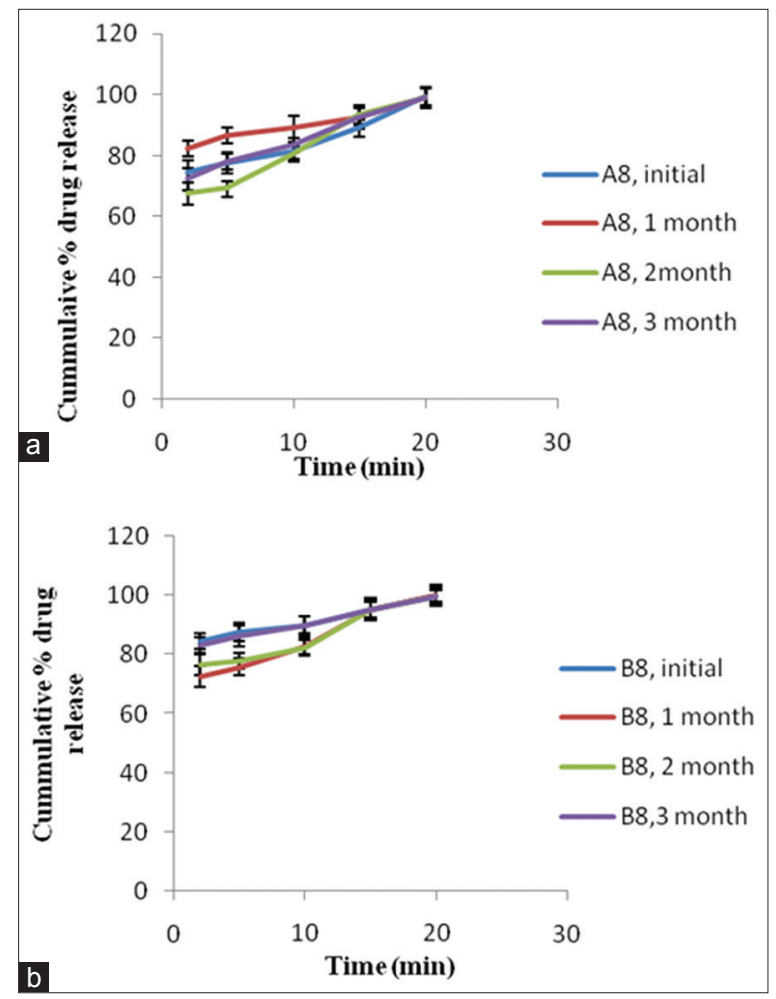

Fig. 4: Percentage drug release of (a) optimized formulation $A_{8}$ at various time intervals (b) optimized formulation $B_{8}$ at various time intervals

Future prospective of the present project comprises in vivo evaluation of the developed formulation in suitable animal model using suitable analytical technique which could not be done during present work due to time constraint and availability of sophisticated instrumentation.

\section{REFERENCES}

1. Hedlund C, Rapoport AM, Dodick DW, Goadsby PJ. Zolmitriptan nasal spray in the acute treatment of cluster headache: A meta-analysis of two studies. Headache 2009;49(9):1315-23.

2. Verma H, Verma S, Prasad SB, Singh H. Sublingual delivery of Frovatriptan: An indication of potential alternative route. Int Sch Res Notices 2014;2014:675868.

3. Bredenberg S, Duberg M, Lennernäs B, Lennernäs H, Pettersson A, Westerberg $\mathrm{M}$, et al. In vitro and in vivo evaluation of a new sublingual tablet system for rapid oromucosal absorption using fentanyl citrate as the active substance. Eur J Pharm Sci 2003;20(3):327-34.
4. Malkawi AH, Al-Ghananeem AM, Crooks PA. Development of a GCMS assay for the determination of fentanyl pharmacokinetics in rabbit plasma after sublingual spray delivery. AAPS J 2008;10(2):261-7.

5. Wang Y, Zuo Z, Lee KK, Chow MS. Evaluation of HO-1-u-1 cell line as an in vitro model for sublingual drug delivery involving passive diffusion-initial validation studies. Int J Pharm 2007;334(1-2):27-34.

6. Senel S, Kremer MJ, Kas S, Wertz PW, Hincal AA, Squier CA. Enhancing effect of chitosan on peptide drug delivery across buccal mucosa. Biomaterials 2000;21(20):2067-71.

7. Smart JD. Buccal drug delivery. Expert Opin Drug Deliv 2005;2(3):507-17.

8. Surapaneni MS, Das SK, Das NG. Effect of excipient and processing variables on adhesive properties and release profile of pentoxifylline from mucoadhesive tablets. Drug Dev Ind Pharm 2006;32(3):377-87.

9. Goswami T, Jasti B, Li X. Sublingual drug delivery. Crit Rev Ther Drug Carrier Syst 2008;25(5):449-84.

10. Wang Y, Zuo Z, Chow MS. HO-1-u-1 model for screening sublingual drug delivery-influence of $\mathrm{pH}$, osmolarity and permeation enhancer. Int J Pharm 2009;370(1-2):68-74.

11. Láinez MJ. Rizatriptan in the treatment of migraine. Neuropsychiatr Dis Treat 2006;2(3):247-59.

12. Shirsat AE, Chitlange SS. Application of quality by design approach to optimize process and formulation parameters of rizatriptan loaded chitosan nanoparticles. J Adv Pharm Technol Res 2015;6(3):88-96.

13. Bayrak Z, Tas C, Tasdemir U, Erol H, Ozkan CK, Savaser A, et al. Formulation of zolmitriptan sublingual tablets prepared by direct compression with different polymers: In vitro and in vivo evaluation. Eur J Pharm Biopharm 2011;78(3):499-505.

14. Klancke J. Dissolution testing orally disintegrating tablets. Dissolut Technol 2003;10(2):6-8.

15. Pabari R, Ramtoola Z. Effect of a disintegration mechanism on wetting, water absorption, and disintegration time of orodispersible tablets. J Young Pharm 2012;4(3):157-63.

16. Marques MR, Loebenberg R, Almukainzi M. Simulated biological fluids with possible application in dissolution testing. Dissolut Technol 2011;18(3):15-28.

17. Shirsand SB, Suresh S, Swamy PV, Para MS, Nagendra Kumar D. Formulation design of fast disintegrating tablets using disintegrant blends. Indian J Pharm Sci 2010;72(1):130-3.

18. Prajapati ST, Patel PB, Patel CN. Formulation and evaluation of sublingual tablets containing Sumatriptan succinate. Int J Pharm Investig 2012;2(3):162-8.

19. Goswami T, Jasti BR, Li X. Estimation of the theoretical pore sizes of the porcine oral mucosa for permeation of hydrophilic permeants. Arch Oral Biol 2009;54(6):577-82.

20. Balusu H, Veerareddy PR. Formulation and evaluation of fast disintegrating Rizatriptan benzoate sublingual tablets. Malays J Pharm Sci 2012;10(1):45-60.

21. International Conference on Harmonisation of Technical Requirements for Registration of Pharmaceuticals for Human Use, ICH Harmonised Tripartite Guideline: Stability Testing of New Drug Substances and Products Q1A (R2). Available from: https://www.ich.org/fileadmin/ Public_Web_Site/ICH_Products/Guidelines/Quality/Q1A_R2/Step4/ Q1A_R2_Guideline.pdf. [Last accessed on 2017 May 07]. 